\author{
Published in Doyon, M. \& Breyer, Th. (eds.), Normativity in Perception, \\ Palgrave Macmillan, 2015, 178-195. \\ PLEASE QUOTE FROM PUBLISHED VERSION
}

\title{
The Normative Force of Perceptual Justification
}

\author{
Arnaud Dewalque
}

\section{Introduction}

From a naturalistic point of view, the world may be seen as a set of physical entities that causally interact. Physical sciences precisely aim at explaining the world by discovering causal transitions between its constituent entities. Similarly, when it comes to the mind, philosophers of a physicalist persuasion typically attempt to account for the place of mind in nature by exploring causal transitions involving mental states. However, our mental life is not just made up of natural processes and causal chains. It involves rational transitions as well. Very roughly, saying that our mental life is also made up of rational transitions simply amounts to saying that, within the sphere of our mental states, some moves are justified while others are not. For instance, my belief that today is Wednesday, given the additional beliefs that school ends at 12 on Wednesday and that I have to go and pick up my children when school ends, doesn't just cause my belief that I have to pick up my children at school at 12. It is also part of what makes it rational for me to believe so. ${ }^{1}$

It is commonly agreed that rational transitions to beliefs or doxastic states exhibit a normative dimension, in the sense that every rational agent should conform to them and be sensitive to their constraining force. In fact, it might be urged that talking about rational transitions and talking about normativity are two ways of describing the same phenomenon. As Peacocke puts it, whenever it is justified to judge that $P$, there is an 'objective norm' according to which judging that $P$ 'is correct, or is likely to be correct' $(2004$, p. 7$)$. One general way to capture this normative character of rational transitions concerning beliefs is to use the following 'should'locution: 'When you are in conditions $C$, you should believe (or refrain from believing) $P$ ' - or, to adopt a more straightforward formulation: 'When in $C$, believe $P$ ' (Pryor, 2014, p. 216).

Granting that 'When in $C$, believe $P$ ' provides us with the general scheme of what may be called an epistemic norm, viz. a norm concerning what we believe, or ought to believe, the question naturally arises which states are likely to figure on the left side of the comma. ${ }^{2}$ In the previous example, conditions $C$ are at least partially given by the joint existence of my belief that today is Wednesday and my belief that school ends at 12 on Wednesday, plus my overall cognitive background. Rational transitions of this kind, however, are far from being restricted to relations from belief to belief. One important claim that attaches to (a certain version of) empiricism is that perceptual experiences, too, are capable of entering into such transitions with beliefs or doxastic states. The idea, roughly, is that having a perceptual experience $E$ can make it rational for me to believe $P$. Consider the following example: I presently see the laptop on the table in front of me. 
The perceptual experience of the laptop supports my belief that there is a laptop in front of me, that the laptop is grey, that the screen is on, and probably other perceptual beliefs as well. To generalize: it seems uncontroversial that perceptual experiences provide me with some 'normative support' for beliefs or judgments about my surroundings (see, e.g., Siegel and Silins, 2015). Moreover, it can be argued that my perceptual experiences also provide me with some normative support for judgments about my own mental states. From the experience of seeing the laptop, for example, I am justified to believe that I presently have a visual experience and that this visual experience is the experience of seeing the laptop. Self-ascription of mental states, however, raises specific issues, and I will not discuss them here.

In this chapter, I focus on one specific class of rational transitions, namely from perceptual experiences to perceptual judgments or beliefs about the external world. To use Pryor's formulation ('When in $C$, believe $P$ '), I will confine myself to an examination of cases where $C$ is a perceptual state (rather than, say, a doxastic state or a set of beliefs) and $P$ is a proposition about the external world (rather than, say, a proposition about my own mental state). Rational transitions of that kind may be called perceptual justifications of beliefs about the external world, but, for the sake of convenience, I will generally omit the precision 'of beliefs about the external world' (so, I will use the phrase 'perceptual justification' as an abbreviation).

Various theories of perceptual justification may be found in the literature. Among them, one basic divide is between reliabilist and internalist accounts of perceptual warrant (Silins, 2012, pp. 243f.). Very roughly, reliabilists hold that considerations about reliability play a crucial role in the explanation of perceptual justification. They look at perceptual experiences 'from the outside'. Internalists, on the contrary, hold that considerations about the conscious character of our perceptual states play a crucial role in the explanation of perceptual justification. They look at perceptual experiences, so to speak, 'from the inside'. Hence, they are bound to connect the epistemological problem of perception with a phenomenological description of perceptual experiences.

It is not my purpose to address the reliabilism-internalism debate here. The approach I favor is broadly internalist or phenomenological. It purports to offer something like an 'inside view' of perceptual justification. One basic idea behind this approach is that perceptual justification is something we commonly experience. In everyday life we not only suppose or claim that our perceptual states have a 'reason-giving force' (Hopp, 2011) or an 'epistemic force' (Schellenberg, 2014) relative to judgments about the external world. We experience that it is so. We feel, so to speak, the normative force of perceptual justification. The question I am interested in is the following: provided that the normative force of perceptual justification is something that manifests itself in consciousness or something we commonly experience, what are the phenomenal features of this experience? To put it differently: what is it to experience the normative force of perceptual justification?

My plan is as follows. In the first section I will briefly comment on the demand of a unified theory of perceptual experiences, viz. a theory that is capable of integrating relevant epistemological and phenomenological aspects of perceptual experiences. In Section 2 I will argue for a way of connecting the epistemological and the phenomenological problem by appealing to a compare-and-contrast strategy. Eventually, in Section 3, I will try to draw some lessons for our understanding of the normative force of perceptual justification. 


\section{In search of a unified theory}

Recent discussions about perceptual experiences articulate two main problems, which are usually referred to as the epistemological problem of perception and the phenomenological problem of perception (see, e.g., Crane, 2001, p. 130; Pautz, 2010, p. 255; Schellenberg, 2014, p. 87). In this section, I will introduce each problem and briefly discuss one oft-traveled route to solve the epistemological problem, namely Propositionalism. Relying upon some recent objections, I will suggest that

Propositionalism is phenomenologically inadequate, and that one plausible therapy consists in connecting in the first place epistemological considerations to phenomenological considerations.

1. Let's start with a brief characterization of the epistemological problem. This problem is relatively easy to set out: it is whether perception provides reasons for belief, and if it does, under which conditions. For example, suppose I enter the room and see a cup of steaming coffee on the table. It is commonly agreed that my experience of seeing the cup of coffee makes me justified in believing certain things rather than disbelieving them or merely suspending my judgment. For example, my visual experience provides normative support for the claims that there is a cup of coffee on the table, that the coffee in the cup is hot, etc. Notice that settling the question as to which propositions are justified by this experience and which are not is part of the epistemological problem of perception. But more on this later.

2. The various formulations of the phenomenological problem that may be found in the literature are less straightforward. One way of addressing this problem is to inquire about the 'phenomenal properties' of perceptual experiences (see, e.g., Pautz, 2010). Yet, for some reasons, I prefer to avoid the phrase 'phenomenal properties'. Maybe a simpler formulation is this: provided that the term 'perception' refers to a cluster of experiences, namely perceptual experiences, what kind of experiences is that? What are their common features? Suppose, again, that I perceive a cup of steaming coffee on the table. The phenomenological question simply is: what makes it the experience it is, from the subjective perspective of me having this experience? This, in turn, involves two distinct questions: (a) in virtue of what does this experience qualify as perceptual rather than, say, imaginative? And (b) what makes this particular perceptual experience different from any other perceptual experience? Hence the phenomenological problem of perception, as I take it, has to do with the general nature of perceptual experiences and their case-by-case individuation. Phenomenological investigation, broadly conceived, aims at making explicit the similarities and dissimilarities between the experiences that compose our mental life, in order to inventory and classify them. As one knows, this task has been labeled phenomenological description by the first representatives of the phenomenological movement, and it is arguably prior to the explanation of our mental states. (see Dewalque, 2013)

It is probably not unfair to say that the epistemological and the phenomenological issues have usually been addressed separately. In my view, Conceptualism and Propositionalism about perceptual experience are prominent views that are symptomatic of such a 'separatist' approach. As a matter of illustration, let us have a look at the way Propositionalists solve the 
epistemological problem.

Propositionalism about perceptual experience is the view that perceptual experiences are relations to propositions or present us with propositions. On this view, my seeing the cup of coffee is more correctly understood as the seeing <that there is a cup of coffee on the table>. The propositional content is supposed to be captured by the that-clause. This is the view famously held by Searle:

The content of the visual experience, like the content of the belief, is always equivalent to a whole proposition. Visual experience is never simply of an object but rather it must always be that such and such is the case. (1982, p. 40)

Clearly the main motivation for Propositionalism is epistemological. It has to do with the idea that perceptual experiences justify beliefs. This fact would be impossible, Propositionalists argue, if perceptual experiences have nonpropositional content: for justification is a logical relation and a state with nonpropositional content cannot stand in logical relation to a state with propositional content. So, relative to the scheme of epistemic norms ('When in $C$, believe $P$ '), Propositionalists hold that any $C$-state must be propositional. Taking for granted that perceptual experiences are $C$ states, perceptual experiences must be propositional. Consider the following passage by Michael Thau:

Many of our beliefs are based on our perceptions. If perception relates subjects to propositions, then this process is no more mysterious than the process of beliefs leading us to other beliefs. However, if perception isn't a relation to a proposition, it is hard to see how there could be inferential relations between perception and belief. (2002, p. 75)

The main argument for Propositionalism, thus, runs as follows:

(i) If perceptual experiences justify judgments, then they have propositional content.

(ii) Perceptual experiences justify judgments.

(iii) Therefore, perceptual experiences have propositional content.

Premise (i) places a constraint upon justification. It presupposes that perceptual justification is inferential and that inferential relations cannot obtain except between states with propositional content. But those claims are highly disputable, and have indeed been disputed.

Let me briefly review the main objections that have been raised against Propositionalism. First, there is no obvious reason why we should accept that perceptual justification is inferential, and why my perceptual experience of seeing the cup of coffee should provide me with a premise for an inference (Chalmers, 2003, p. 251; for further discussions, see Pryor, 2014; Siegel and Silins, 2015). Second, assuming that the content of my perceptual experience may be captured by means of a proposition, it is difficult to see why we should capture the perceptual content by means of one proposition rather than another. What is the propositional content of my experience of seeing this cup of steaming coffee: is it that this cup is white? That there is a cup of coffee on the table? That the cup is filled with hot coffee? Actually, each proposition should be regarded as a description of the content of my perceptual experience. Now, if each proposition selectively 
captures one aspect of my visual content, none of them can be regarded as giving the content itself. The observation that a perceptual content may be expressed by a 'that' clause doesn't imply that it is the best - let alone the only - way to express it. It is just one convenient way of modeling perceptual contents (see Crane, 2009/2014). Third, it may be argued that the contents of perceptual experiences and the contents of beliefs have a different structure, to the effect that they cannot be identical with one another. Consider again my visual experience of this cup of coffee. It presents me with an overall visual scene (which in turn is a part of my overall perceptual field, including audition and the like). To some extent, the situation is comparable to the contemplation of a picture. Each part of the picture is connected to the others in a quite different a way than concepts and propositions are connected to one another. As Crane puts it:

Just as pictures are not true or false, so they do not stand in logical relations. Complex pictures do not stand to their pictorial parts as complex propositions stand to their consistent propositions. Pictures do not imply one another; they cannot be negated or disjoined. (2009/2014, p. 223)

Negation, conjunction, disjunction, consistence, contradiction and the like are logical relations that obtain in the domain of concepts and propositions. If perceptual contents are propositional, then they should be structured by the same relations. This claim, however, sounds implausible. More pointedly, one could insist that propositional contents exhibit a kind of separability which perceptual contents lack. I can believe $(P)$ that the cup of coffee is on the table without believing $(Q)$ that it is white. $P$ and $Q$, as propositional contents, prove to be quite separable from one another. By contrast, I cannot see the cup on the table without somehow seeing its color. Unlike doxastic contents, perceptual contents do not show the same kind of separability. Therefore, assuming that separable parts and non-separable parts cannot be identical, and that two wholes with different parts are different wholes, perceptual contents cannot be identical to propositional contents (for a detailed argumentation along those lines, see Almäng, 2014).

I think those objections are sound. In my view, the worry with Propositionalism has its source in the fact that Propositionalists, while tackling the epistemological problem of perception, often neglects its phenomenological dimension. My own contention is that accounts starting with epistemological considerations and ending up with claims about the nature (and structure) of perceptual experiences go the wrong way. If we want a fair description of perceptual experiences, we should better not try to deduce their features from epistemological considerations about what is likely to enter into a rational relation with a perceptual judgment. In this respect, Crane is right in saying that 'it is a mistake to read back from the content of a perceptual judgment a hypothesis about the structure of experience on the basis of which it is made' (Crane, 2009/2014, p. 230). The phenomenology of perceptual experiences is prior to their epistemology.

If this is true, there are good reasons to think that tackling the epistemological problem and the phenomenological problem separately won't give rise to a satisfying theory of perceptual justification. Accordingly, several voices recently begun to demand a 'unified account' of perceptual experiences that could integrate their relevant epistemological and phenomenological aspects (e.g., Hopp, 2011; Silins, 2012; Schellenberg, 2014). This suggests that a more promising approach of perceptual justification might be developed if we find a way to connect epistemological and phenomenological considerations. 


\section{The method of contrast}

In this section I want to suggest a way of connecting the epistemological problem of perception (under what conditions do perceptual experiences warrant perceptual beliefs?) to the phenomenological problem (what makes our perceptual experiences the experiences they are?). The strategy I have in mind is a compare-and-contrast strategy, and is close to what has sometimes been called the method of phenomenal contrast (Siegel, 2007/2010; Kriegel, 2007). It consists in contrasting perceptual experiences with other kinds of experiences, which either lack normative force (like imagining) or exhibit a different kind of normative force (like believing). Since I do not intend to provide a full-blown theory of perceptual justification, I will restrict myself to some aspects that are relevant for the present purposes (for a more detailed survey, see Siegel and Silins, 2015).

First, it is obvious that the normative force proper to perceptual justification has to do with the character of our perceptual experiences and doesn't manifest itself in non-perceptual states like, say, imaginative states. I can close my eyes and imagine that there is a cup of steaming coffee on the table. I thereby form a 'mental picture' of the cup of coffee. This imaginative state, however, doesn't provide me with the least reason to think that the world is the way I represent it in imagination. Unlike seeing this cup of coffee, imagining this cup of coffee is a state that lacks any reason-giving force. Imaginative states cannot work as justifiers for our beliefs about the external world.

Second, it has already been suggested that one single perceptual experience provides normative support for more than just one perceptual belief. In the case of the experience of the cup of coffee, possible candidates for perceptually justified beliefs include, for example, the belief that there is something thus shaped and colored: the belief that there is a cup of steaming coffee on the table, the belief that the cup is not empty, the belief that the coffee is hot, the belief that my wife is already back from work (assuming she drinks coffee at home and I don't), and the belief that I presently have a visual experience of a cup of steaming coffee (that is, a belief about my own mental state or about the nature of my present experience). Clearly these are different beliefs. The question about which of them, if any, is 'spontaneously' formed on the basis of my experience is certainly dependent upon contextual factors, such as the circumstances in which I have the experience, plus my overall cognitive background. Nevertheless, each of those judgments seems to be a plausible candidate for being justified by my visual experience of seeing the cup of coffee. By contrast, the belief that my wife has dark hair or the belief that there is mustard in the fridge, though being arguably perceptual judgments too, are not good candidates for obvious reasons: they prima facie have nothing to do with my seeing the cup of coffee; hence, they cannot be justified by this experience. This suggests that, for the belief that $P$ to be justified by a perceptual experience $E$, there must be some suitable connection between $P$ and $E$, whatever this connection may be.

Third, it is rather obvious that my perceptual experience of seeing the cup of coffee, if it potentially justifies all the candidates I have just mentioned, doesn't justify each of them in exactly the same way. This suggests that there are various kinds of perceptual justification. For instance, it might be argued that the very fact of seeing the cup implies the grasping of its shape and color. At least on a normal understanding of 'seeing', it is hard to figure out how I could say at the same time 'I see this cup of coffee' and 'I don't see its shape and color', for seeing the 
cup's shape and color is just part of what it is to see the cup. Hence, it is tempting to say that my visual experience, in the absence of defeaters, provides me with some immediate justification for believing that there is something thus shaped and colored. In contrast to such cases, it seems that something more than my visual experience is required for me to be justified in believing that my wife is already back from work. The transition from the perceptual experience of seeing the cup of steaming coffee to the belief that my wife is back from work certainly is no less rational than in the previous case. Yet it seems that, for the rational transition to obtain here, at least one additional background belief is required: for instance, the belief that my wife usually drinks coffee when she is back from work. One way to capture this contrast is to say that this last case is a case of 'mediate' justification, as opposed to 'immediate' justification (Pryor, 2000, p. 532). ${ }^{3}$ One lesson is that not every perceptual justification needs to be immediate justification assuming there is immediate justification at all, but I won't discuss this assumption here (for a defense, see Pryor, 2014).

Four, perceptual justification arguably has a normative force of a different kind than the normative force of mere doxastic justification. Consider again the initial today-is-Wednesday example. My belief that I should go and pick up my children at school at 12 is (partly) justified by my belief that today is Wednesday. But my belief that today is Wednesday requires in turn some justification and is not self-justifying. After all, someone could ask me: what is your reason for thinking (believing, assuming, etc.) that today is Wednesday? And her question would make perfect sense. By contrast, it seems that my seeing the cup of coffee works as a justifier without requiring any further justification. Someone could ask me: what is your reason for thinking that there is a cup of coffee on the table? But it would make no sense to ask: what is your reason for perceiving this cup of coffee? This suggests that perceptual experiences, unlike beliefs and judgments, are not justified by anything and, so to speak, cannot borrow their normative force from something else. This is why they are usually considered regress-stoppers in the construction of justification chains.

To sum up, the application of the method of contrast so far has highlighted a number of aspects that may be regarded as constitutive of what it is to feel the normative force of perceptual justification. Those aspects may be tentatively captured by the following definition:

\section{Perceptual Justification}

For any experience $\mathrm{E}$ and for any proposition $\mathrm{P}, \mathrm{E}$ perceptually justifies the belief that $\mathrm{P}$ if and only if (i) $\mathrm{E}$ has reason-giving force, (ii) $\mathrm{E}$ is suitably connected to $\mathrm{P}$, and (iii) $\mathrm{E}$ doesn't call for further justification.

Importantly, this definition suggests that there is at least an epistemic contrast between seeing, imagining, and believing. My seeing the cup of coffee justifies the belief, say, that there is a cup of coffee on the table, while my imagining the cup of coffee doesn't. It lacks any reason-giving force. Moreover, my belief that there is a cup of coffee on the table may work as a justifier for other beliefs (e.g., that my wife is already back from work); but, unlike my seeing the cup of coffee, my belief that there is a cup of coffee on the table is not a regress-stopper: it calls in turn for some other justifier. The contrast here, again, is epistemic.

Now, it might be insisted that those contrasts are phenomenological as well. After all, 
disregarding their epistemological status, the experience of seeing the cup of coffee on the table is not the same experience as imagining that there is a cup of coffee on the table or the experience of believing that there is a cup of coffee on the table. Even if we bracket the specific reasongiving force of perceptual experiences, we do not confound them with imaginative or doxastic experiences. This suggests that there is a certain matching between epistemological contrasts and phenomenological contrasts. Therefore, describing the phenomenological contrasts between seeing, imagining, and believing might be a good way of explaining the epistemological contrasts between them. This is the business of the next section.

\section{Object, content, and attitudinal force}

I have suggested so far that Propositionalism is phenomenologically inadequate and that a crucial step towards a more promising theory of perceptual justification can be made by accounting for a number of epistemological and phenomenological contrasts. In this section I discuss various ways of accommodating the contrasts I mentioned above. I start with the contrast between states that are suitably connected and states that are not.

1. It is clear that Propositionalists have a ready-made story to account for this kind of connection. According to Propositionalism, my seeing that there is a cup of coffee on the table is suitably connected to my believing that there is a cup of coffee on the table in virtue of having the same propositional content. Call this the Same Content Hypothesis. This hypothesis provides us prima facie with a straightforward explanation of why my seeing the cup of coffee has reasongiving force, relative to my belief that there is a cup of coffee on the table, but lacks any reason-giving force relative to my belief that my wife has dark hair. As we have seen, however, the claim that perceptual experiences have propositional content is question-begging and does not seem to capture the phenomenology of perceptual experiences. Anti-Propositionalist objections, as I have recalled above, suggest that perceptual experiences just do not relate us to propositions. More importantly, it seems that the reasons we have for rejecting Propositionalism are also reasons for rejecting the Same Content Hypothesis. If the world simply is not represented in the same way in perception and in belief, then perception and belief cannot have exactly the same representational content. My visual experience of the cup of coffee presents me with a whole visual scene, in all its complexity, whereas my judgment that there is a cup of coffee on the table captures only one aspect of the visual experience and remains silent on the others. After all, the judgment says nothing about the color of the cup, or its exact position on the table, etc. To be sure, on the basis of my visual experience, I can form other judgments capturing those further aspects of the visual scene. Yet they are precisely other judgments, while the non-propositional content of my visual experience remains basically the same. To sum up, any satisfying attempt to explain the suitable connection between the perceptual experience $E$ and the belief that $P$ ('When in $E$, belief $P$ ') should be compatible with the claim that $E$ represents the world in a non-propositional way. And if it is so, the suitable connection we are after cannot be thought of as an identity of perceptual and doxastic contents, since perceptual contents are non-propositional, while doxastic contents are propositional.

What alternative do we have? One obvious solution would be to appeal to the notion of an 'intentional object' (Crane, 2001; Hopp, 2011). The idea, basically, is the following. Certainly my seeing the cup of coffee and my belief that there is a cup of coffee on the table have distinct contents: they represent the cup of coffee in quite different ways. Nevertheless, in contrast to the 
relation between my seeing the cup of coffee and my belief that my wife has dark hair, they seem to have something in common. The commonality between them, it is suggested, may be expressed by saying that they are about the same object, namely the cup of coffee. Let us label this the Same Object Hypothesis. According to the Same Object Hypothesis, for any state A and for any state $B, A$ has reasongiving force relative to $B$ if and only if $A$ and $B$ are intentional states about the same object. This solution is appealing, for it allows us to account for the connection between seeing and believing without forcing the act of seeing into the propositional scheme of inferential justification. The Same Object Hypothesis, thus, seems to be more adequate to the phenomenology of perceptual experiences. ${ }^{4}$ Accordingly, our initial definition might be modified as follows:

\section{Perceptual Justification*}

For any experience $\mathrm{E}$ and for any proposition $\mathrm{P}, \mathrm{E}$ perceptually justifies the belief that $\mathrm{P}$ if and only if (i) $\mathrm{E}$ has reason-giving force, (ii) $\mathrm{E}$ has the same object as the belief that $\mathrm{P}$, and (iii) E is doesn't call for further justification.

Does (ii) adequately capture the constraint that $P$ should be suitably connected to $E$ ? I think there are reasons to be skeptical about this. Suppose $P$ is the proposition that $<$ this cup of coffee is red $>$ and $E$ is a visual experience of a white cup of coffee being in front of me. $E$ arguably has the same intentional object as (the belief that) $P$. Nevertheless, in this case, it is obvious that $E$ doesn't support the belief that <this cup of coffee is red $>$. This suggests that, if we want a plausible understanding of the 'suitable connection' between $P$ and $E$, the Same Object Hypothesis must be supplemented. We need something like the idea that the propositional content of the perceptually justified belief is somehow 'congruent' with the perceptual content of $E$. Thus, a more plausible formulation would be to the following:

\section{Perceptual Justification**}

For any experience $\mathrm{E}$ and for any proposition $\mathrm{P}, \mathrm{E}$ perceptually justifies the belief that $\mathrm{P}$ if and has the same object as the belief that $\mathrm{P}$, (iii) $\mathrm{P}$ represents its object in a way that is congruent with E, and (iv) E is doesn't call for further justification.

2. What I have just said certainly is a first step to illuminate the normative force of perceptual justification. Yet, it cannot be the whole story, for the Same Object Hypothesis (plus content partial congruence) also holds for the normative character of doxastic justification ('When in doxastic state $S$, belief $P^{\prime}$ '), and what we seek here is an insight into perceptual justification ('When in perceptual state $E$, belief $P$ '). In other words, we still need to account for the fact that $E$ (i) has a reasongiving force and (iii) works as a regress-stopper. Unlike imagining the cup of coffee, seeing the cup of coffee is reason-giving relative to a range of beliefs. And unlike believing that there is a cup of coffee on the table, seeing the cup of coffee doesn't call for any further justification whatsoever.

Now, one way of accounting for this dual contrast is to locate it within the representational contents of our experiences. This is, more or less, the representationalist view championed by Fred Dretske (1995) and Micheal Tye (1995) - among many others. According to Representationalists, our perceptual experience of seeing this cup of coffee is basically a matter 
of how the world appears to us in perception. On this account, there is no intrinsic distinction to be made between two mental states except that they have different representational contents.

Suppose, for example, that you enjoy two experiences, $A$ and $B$, no matter whether they are imaginative, perceptual or doxastic states. According to pure representationalism, saying that $A$ is not $B$ amounts to saying that $A$ and $B$ do not have the same content. They represent the world as being in two different ways. In other words:

\section{Strong Representationalism}

Two mental states, $\mathrm{A}$ and $\mathrm{B}$, differ from one another if and only if they have distinct contents, $\mathrm{C}_{1}$ and $\mathrm{C}_{2}$.

On this account, then, the difference between perceiving and imagining is nothing but a difference in content. Roughly speaking, this view brings us back to Hume's famous distinction between impressions and ideas. Imaginative contents are weak and less vivid than perceptual contents. Similarly, Strong Representationalists may locate the difference between perceiving and believing in the related contents: while the content of belief is conceptual and/or propositional, the content of perception arguably shows a non-conceptual dimension.

The main motivation for Strong Representationalism is the so-called argument from transparency (Moore, 1903, p. 446; Hartman, 1993; Tye, 1995). Experienced features, on this view, are not features of experience itself; rather, they are features of what is represented in experience. Hence, Strong Representationalists have been reluctant to accept the existence of intrinsic features of experiential states. However, I think Representationalists are wrong in rejecting the idea of intrinsic features of experience on the basis of the transparency argument. The reason is that the transparency argument has several pitfalls and cannot work unless it is supplemented by additional assumptions, which are debatable (see Dewalque and Seron, 2015).

Just consider the following con-argument, which I will call The Argument from Discrimination. A normal subject in normal circumstances is able to discriminate between a perceptual state $A$ and an imaginative state $B$. Now suppose, for the sake of the argument, that $A$ and $B$ are states with exactly the same content. After all, if you have a vivid imagination, it seems it is not impossible for you to imagine a scene that is as clear and vivid as in perception. Still, a normal subject will not confound $A$ and $B$. It still has the ability to distinguish a perception from an imagination, even if the object that is perceptually represented is the same as the object that is imaginatively represented, and even if this object is represented in exactly the same way. A formulation of the argument may be found in Huemer (2001, p. 77):

Even if you have a very vivid, very detailed imagination, or if you have very poor eyesight, you still would never confuse seeing a tomato with imagining one. The reason lies in what I call the 'forcefulness' of perceptual experiences: perceptual experiences represent their contents as actualized; states of merely imagining do not. When you have a visual experience of a tomato, it thereby seems to you as if a tomato is actually present, then and there. When you merely imagine a tomato, it does not thereby seem to you as if a tomato is actually present. 
As Farkas $(2013, \S 4)$ puts it, content vividness and clarity are neither sufficient nor necessary conditions for qualifying an experience as perceptual rather than imaginative. If it is right that a perceptual state and an imaginative state can have exactly the same content (even though I'm aware that this claim is debatable), then the absence of confusion can hardly be explained by appealing to a difference in content. Representationalism, it may be concluded, actually fails to account for the difference between seeing and visually imagining. Since this difference is arguably not (or not only) a difference in content, it needs to be located elsewhere.

Fortunately, there is an alternative: the difference could be located in the 'intentional mode' or 'attitude'. As a matter of fact, the significance of the attitudinal dimension of perceiving has been more and more acknowledged over the last decade under various labels: 'phenomenal force' (Pryor, 2000), 'forcefulness' (Huemer, 2001), 'feeling of presence' (Matthen, 2005; 2010), or 'sense of reality' (Farkas, 2013). The common idea behind those approaches is that there is more to perceptual justification than just inferential relations between conceptual contents. One of the most prominent supporters of this view is certainly Pryor:

Our experience represent propositions in such a way that it 'feels as if' we could tell that those propositions are true - and that we're perceiving them to be true - just by virtue of having them so represented [...]. I think this 'feeling' is part of what distinguishes that attitude of experiencing that $p$ from other propositional attitudes, like belief and visual imagination. Beliefs and visual images might come to us irresistibly, without having that kind of 'phenomenal force'. (2000, p. 547, fn. 37)

Clearly, Pryor's phenomenal force is bound to explain the epistemic and phenomenal contrasts between seeing, believing, and imagining. Now, what is exactly this phenomenal force? Provided it is not something that has to do with content but rather with perceptual attitude, what kind of attitude is it? Armstrong (1968) famously held the view that perceptual attitudes are akin to beliefs or doxastic attitudes, but this view doesn't come without difficulties. Above all, it seems unable to explain the contrast between seeing the cup of coffee on the table (which is a regressstopper state) and believing that the cup of coffee is on the table (which needs further justification). Moreover, Pryor's description suggests that the so-called phenomenal force has nothing to do with doxastic 'irresistibility': it is not that my visual experience of the cup of coffee would be accompanied by an irresistible belief that the visual scene is real, even if the phenomenal force - or the feeling of presence -, as Matthen (2005, p. 305) suggests, seems to have some similarity with assertion.

Like Pryor, and unlike Hopp (2011, pp. 113ff.), I suspect that a fullblown account of the normative force of perceptual justification should account somehow for the phenomenal or attitudinal force of perceptual experiences. On the face of it, it seems plausible to maintain that this aspect of perceptual justification is tied to the fact that my visual experience has reasongiving force and doesn't call for further justification (parts (i) and (iv) of the above definition of Perceptual Justification**). Clarifying the exact nature of this 'attitudinal force' and its connection to the normative force of perceptual justification would be the task of further investigations.

\section{Notes}


1. The idea that causal transitions and rational transitions must be kept apart has been famously championed by Sellars (1956/1997), Davidson (1986/2001), and McDowell (1994/1996). In their terminology, while causal transitions take place within the 'logical space of nature', rational transitions take place within 'the logical space of reasons'.

2. Clearly, rational transitions don't just have bearings on what we believe, as in the case of epistemic norms. They also have bearings on the way we act. Imagine, for example, the somewhat improbable scenario that my laptop suddenly ignites. Given that I see the flames and feel their heat, it is rational for me to remove my hands from my laptop's keyboard to avoid serious burns. As Berkeley famously insisted, vision is action-guiding: 'Upon the whole, I think we may fairly conclude that the proper objects of vision constitute an universal language of the Author of Nature, whereby we are instructed how to regulate our actions in order to attain those things that are necessary to the preservation and wellbeing of our bodies, as also to avoid whatever may be hurtful and destructive of them. It is by their information that we are principally guided in all the transactions and concerns of life' (Berkeley, 1709/1901, § 147, p. 200). On rational transitions from perceptual experience to action, see Doyon (this volume).

3. Some people deny that perceptual justification may be immediate and reject foundationalism. In this chapter I simply assume without argument that some version of 'modest' foundationalism is true. According to 'modest' foundationalism, as opposed to Cartesian foundationalism, the existence of basic beliefs does not entail the existence of infallible, incorrigible, self-evident, or self-justifying beliefs. See, for example, Pryor (2000, p. 537 and 2001, p. 102), Feldman (2003, pp. 70f.).

4. One plausible argument for the Same Object Hypothesis wouldhavetheformof an inference to the best explanation:(1) There is a contrast between states that are suitably connected and states that are not.(2) The Same Object Hypothesis is the best way to explain this contrast.(3) Therefore, there is a presumption in favor of the Same Object Hypothesis.

\section{References}

Armstrong, D. (1968) A Materialist Theory of the Mind (New York: Humanities Press).

Almäng, J. (2014) 'Perception, non-propositional content and the justification of perceptual judgments', Metaphysica, 15(1), 1-23.

Berkeley, G. (1709/1901) An Essay towards a New Theory of Vision. Reprinted in The Works of George Berkeley (Oxford: Clarendon Press).

Chalmers, D. (2003) 'The content and epistemology of phenomenal belief' in Q. Smith, A. Jokic (eds)

Consciousness. New Philosophical Perspectives (Oxford: Oxford University Press), pp. 220-72.

Crane, T. (2001) Elements of Mind (Oxford: Oxford University Press).Crane, T. (2009) 'Is perception a propositional attitude?', Philosophical Quarterly,

59, 452-69 (reprinted in Crane, 2014, pp. 216-34).Crane, T. (2014) Aspects of Psychologism (Cambridge, MA: Harvard University Press). Davidson, D. (1986) 'A coherence theory of truth and knowledge' in E. LePore

(ed.) Truth and Interpretation. Perspectives on the Philosophy of Donald Davidson (London: Blackwell), pp. 307-19; reprinted in Davidson, D. (2001) Subjective, Intersubjective, Objective (Oxford: Clarendon Press), pp. 137-53. 
Dewalque, A. (2011) 'Expérience perceptuelle et contenus multiples', Bulletin d'analyse phénoménologique, 7(1), 153-85.

Dewalque, A. (2013) 'Brentano and the parts of the mental: a mereological approach to phenomenal intentionality', Phenomenology and the Cognitive Sciences, 12(3), 447-64.

Dewalque, A., Seron, D. (2015) 'Existe-t-il des phénomènes mentaux?', Philosophie, 124, 105-26.

Farkas, K. (2014) 'A sense of reality' in F. Macpherson, D. Platchias (eds) Hallucinations (Cambridge, MA: MIT Press), pp. 399-417.

Feldman, R. (2003) Epistemology (Englewood Cliffs: Prentice Hall).Huemer, M. (2001) Skepticism and the Veil of Perception (Lanham: Rowman \&

Littlefield).Hopp, W. (2011) Perception and Knowledge. A Phenomenological Account (Cambridge:

Cambridge University Press).Kriegel, U. (2007) 'The phenomenologically manifest', Phenomenology and the

Cognitive Sciences, 6, 115-36.Matthen, M. (2005) Seeing, Doing, and Knowing. A Philosophical Theory of Sense

Perception (Oxford: Oxford University Press).Matthen, M. (2010) 'Two visual systems and the feeling of presence' in $\mathrm{N}$.

Gangopadhyay, M. Madary, F. Spicer (eds), Perception, Action, and Consciousness: Sensorimotor Dynamics and Two Visual Systems (Oxford: Oxford University Press), pp. 107-24.

Pautz, A. (2010) 'Why explain visual experiences in terms of content?' in B. Nanay (ed.) Perceiving the World (Oxford: Oxford University Press), pp. 254-309. Peacocke, C. (2004) The Realm of Reason (Oxford: Oxford University Press).

Pryor, J. (2000) 'The skeptic and the dogmatist', Noûs, 34(4), 517-49.Pryor, J. (2001) 'Highlights of recent epistemology', The British Journal for the

Philosophy of Science, 52(1), 95-124.Pryor, J. (2014) 'Is there immediate justification?' In M. Steup, J. Turri, E. Sosa

(eds) Contemporary Debates in Epistemology (London: Blackwell).Schellenberg, S. (2014) 'The epistemic force of perceptual experience', Philosophical

Studies, 170, 87-100.Searle, J. (1982) Intentionality. An Essay in the Philosophy of Mind (Cambridge:

Cambridge University Press).

Sellars, W. (1956) 'Empiricism and the philosophy of mind' in H. Feigl, M. Scriven (eds) Minnesota Studies in the Philosophy of Science (Minneapolis: University of Minnesota Press). Reedited (2001) with an introduction by R. Rorty (Cambridge, MA: Harvard University Press).

Siegel, S. (2007) 'How can we discover the contents of experience?', Southern Journal of Philosophy, 45, 127-42. Reprinted in Siegel (2010, pp. 77-96). 
Siegel, S. (2010) The Contents of Visual Experience (Oxford: Oxford University Press).

Siegel, S., Silins, N. (2015) 'The epistemology of perception' in M. Matthen (ed.) The Oxford Handbook of the Philosophy of Perception (Oxford: Oxford University Press).

Silins, N. (2011) 'Seeing through the "veil of perception"', Mind, 120, 329-67. Silins, N. (2012) 'Explaining perceptual entitlement', Erkenntnis, 76, 243-61. Thau, M. (2002) Consciousness and Cognition (Oxford: Oxford University Press). 